\title{
Estrategias del uso del espacio intrasitio en cazadores- recolectores del Bajo de Sarmiento durante el Holoceno tardío (Chubut, Argentina)
}

\section{Santiago Peralta González}

\author{
Fecha de defensa: 15 de mayo de 2020 \\ Directora: Dra. Liliana Manzi \\ Co-director: Dr. Eduardo Moreno \\ Jurados: Dras. Karen Borrazzo, Laura Miotti y Cecilia Pérez \\ de Micou
}

\section{Introducción}

El tema que desarrollé en mi Tesis Doctoral fue el estudio de las estrategias de movilidad y asentamiento que emplearon los cazadores-recolectores que habitaron el Bajo de Sarmiento (Sarmiento, Chubut) (Figura 1) durante el Holoceno Tardío (ca. 1500 AP), a través del análisis intrasitio de los conjuntos ergológicos recuperados mediante excavaciones y recolecciones superficiales. La forma de abordar los estudios de los sitios arqueológicos propuesta es poniendo énfasis en la dimensión espacial del registro (Borrero et al., 1992), a partir de la utilización de Sistemas de Información Geográfica (SIG). Dentro del conjunto de herramientas se privilegiaron las geoestadísticas, a los efectos de obtener patrones de distribución; explorando la variabilidad de la evidencia arqueológica (Binford, 1982, 1995) en el uso del espacio a través del tiempo De este modo, se construyó una interpretación acerca de las características de las distribuciones de evidencia arqueológica de los sitios bajo estudio, lo que permitió reconocer diferencias y similitudes que posibilitaron describir la variabilidad de las estructuras espaciales intrasitio, e inferir las potenciales estrategias de uso del espacio. De este modo, los objetivos generales fueron:

1. Comprender las estrategias de movilidad a partir del análisis del espacio intrasitio. El análisis acerca del uso del espacio en tiempos pasados permite pensar cómo se configuraron las actividades humanas a través del tiempo. En tal contexto, el estudio detallado del patrón de asentamiento como elemento analítico del registro arqueológico, hace posible el abordaje de una dimensión espacial de la complejidad y dinámica social.

2. Construir un modelo de estructuración espacial intrasitio para grupos de cazadores-recolectores que habitaron el Bajo de Sarmiento.

\footnotetext{
* Instituto de Diversidad y Evolución Austral (IDEAus), Centro Nacional Patagónico (CENPAT), Consejo Nacional de Investigaciones Científicas y Técnicas (CONICET). Boulevard Alte. Brown 2915 (CP U9120ACD) Puerto Madryn, Chubut, Argentina. E-mail: peraltagonzalezsantiago@gmail.com
}

3. Efectuar un aporte metodológico para la construcción de un modelo general de la estructuración de sitios estratificados a cielo abierto.

En tanto que los objetivos específicos se orientaron a:

» Proponer modelos de organización intrasitio, reconociendo principios generales de estructuración, analizando la distribución intrasitio de materiales líticos y óseos, de estructuras de combustión y huellas de poste, a efectos de explorar la variabilidad intrasitio entre los tres casos analizados.

"A través del modelo de estructuración intrasitio, generar un diseño de muestreo que permita seleccionar sectores y muestras en otros sitios del área con similares características.

" A partir de la variabilidad intrasitio, acceder al reconocimiento de las estrategias de movilidad y asentamiento que emplearon los cazadores-recolectores que habitaron el Bajo de Sarmiento. En este sentido, al analizar a través de la evidencia contenida en sitios específicos, se alcanza una visión regional en función de las características de los materiales arqueológicos, dado que refieren al espacio regional, al hacer referencia a circuitos de movilidad en función de las procedencias que puedan ser atribuidas a los distintos ambientes que fueron visitados / recorridos.

\section{Marco teórico-metodológico}

Los patrones distribucionales a escala micro, conformados por un amplio espectro de materiales, proporcionan un contexto espacial que sirve para entender conductas humanas a través del tiempo, por lo tanto, evaluar las estrategias de ocupación del espacio es una línea de análisis que permite entender el aprovechamiento que las sociedades hacían de los recursos disponibles. Es por ello que detectar tendencias, cambios y continuidades se convierte en un aspecto provechoso para comprender la trayectoria de esas sociedades a lo largo del tiempo. Estas interpretaciones fueron realizadas sobre la base conceptual elaborada para estrategias de movilidad y asentamiento de tipo collectors (Binford, 1995). Para poder reconstruir estas prácticas se utilizaron como indicadores de estructuración espacial interna rasgos como fogones y huellas de poste, estructuras conformadas por bloques de basalto, y patrones de distribución formados por el registro artefactual y arqueofaunístico. 


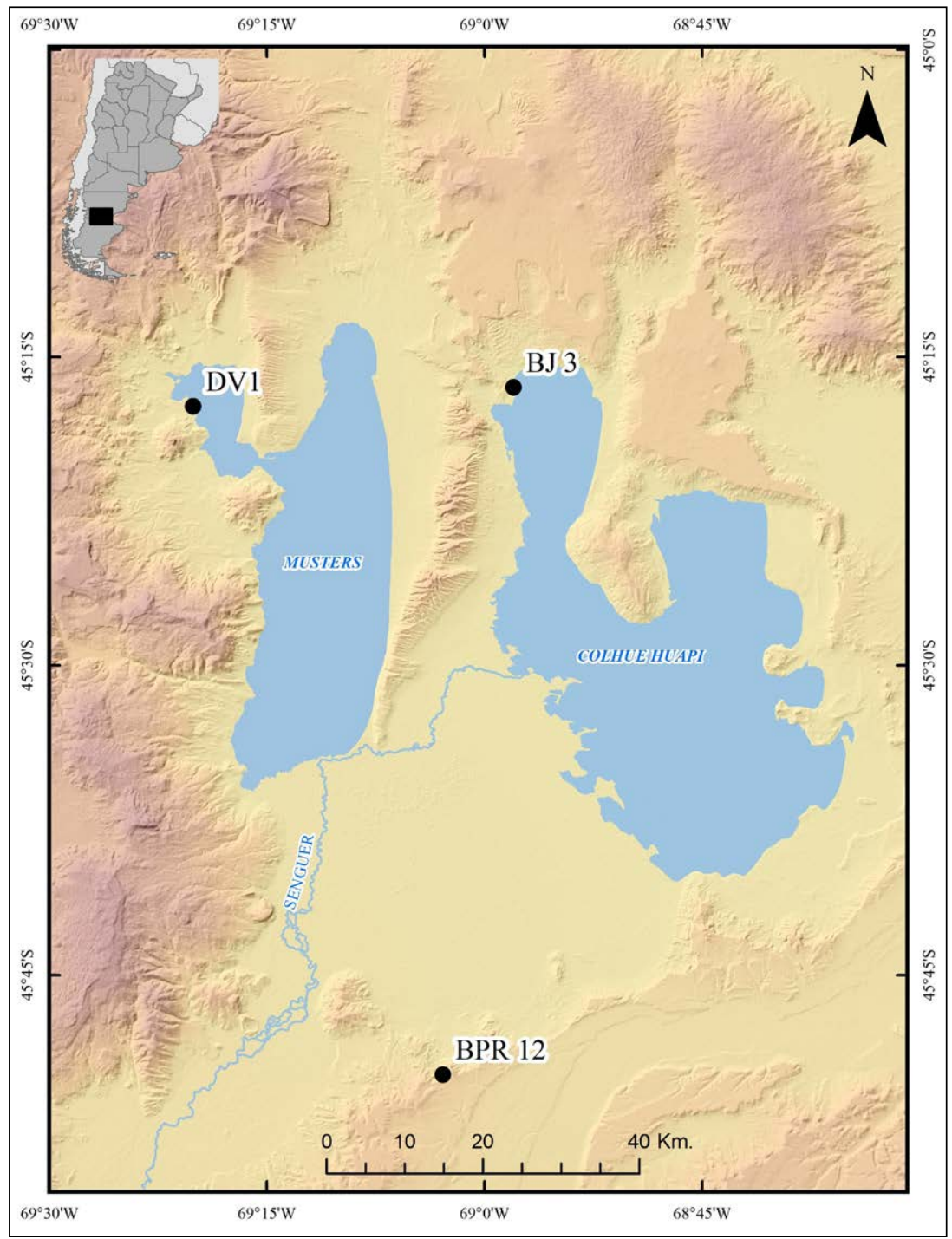

Figura 1. Ubicación de los sitios analizados.

Las estrategias metodológicas utilizadas se inscriben en la Arqueología Espacial, y permitieron la detección de patrones espaciales de la evidencia arqueológica, a partir del empleo de métodos de análisis sistemáticos (Hodder y Orton, 1976). Este acercamiento cuantitativo permitió evidenciar tendencias, pautas y relaciones espaciales en las distribuciones registradas, lo cual permite poner a prueba hipótesis que expliquen los procesos causales de los registros. Además, de ofrecer la capacidad de manejar grandes volúmenes de datos, también permite generar modelos predictivos sobre la localización, importancia y funcionamiento de los yacimientos (Hodder y Orton, 1976).

El enfoque distribucional intrasitio se ha beneficiado por el desarrollo y aplicación de Sistemas de Información Geográfica (SIG) para el procesamiento digital de imágenes y la aplicación de estadísticas, como herramienta fundamental para superar los análisis basados en observaciones meramente ilustrativas y favorecer la cuantificación de la información espacial, y a fines de contribuir a la construcción de una explicación causal de los patrones distribucionales observados. El análisis espacial desde una perspectiva geoestadística tuvo como objetivo principal caracterizar la evidencia material de las acciones sociales y naturales, localizadas en un punto determinado del espacio (Baxter, 2015; Ducke, 2015; Maximiano Castillejo, 2013, 2016).

Se ha desarrollado una metodología que en la actualidad se emplea de manera escasa, y que es aplicable a distintos contextos arqueológicos, tanto para sitios a cielo abierto como para aleros y cuevas, permitiendo la construcción de un referente empírico enriquecido por el estudio de las relaciones espaciales a escala intrasitio, a partir de la utilización de un sistema de información geográfica (SIG).

Desde esta perspectiva de análisis a escala intrasitio, la Tesis se centró en la caracterización funcional y el estudio de la organización espacial interna de los sitios Delta Vulcana 1 (DV1) (1400 años AP), Bosque Petrificado 12 (BPR12) (1230 años AP) y Boliche de Jeréz 3 (BJ3) (1500 AP), lo cual posibilitó 
vincular la distribución espacial de los materiales arqueológicos con procesos antrópicos y naturales para elaborar explicaciones acerca de los modos de organización y uso del espacio a escala intrasitio en grupos de cazadores-recolectores del área. Debido a su buena preservación, se consideró al sitio DV1 como la evidencia de base para la elaboración de un modelo de estructuración intrasitio, puesto que se considera que en él se han conservado las ubicaciones originales de los materiales arqueológicos, como también la integridad de las estructuras (Moreno y Peralta González, 2020; Moreno y Pérez Ruíz, 2010). La minuciosidad con la que fue relevada la información durante las excavaciones, sumado al detalle con el que realizaron los análisis de los materiales recuperados, lo posicionan como un referente de estudio a partir del cual se prevé describir la variabilidad y las regularidades en las que se expresa la configuración espacial del registro arqueológico, respecto de los otros sitios involucrados en este trabajo.

\section{Discusión y conclusiones}

A partir de los análisis sobre los sitios arqueológicos, se han podido interpretar algunos aspectos referidos a las estrategias de asentamiento en sociedades que habitaron en el pasado. Para ello, se construyó un modelo de estructuración intrasitio que pudiera ser aplicado a otros sitios del área y así constituir una herramienta de interpretación de distribuciones arqueológicas a cielo abierto, ubicadas cronológicamente en el Holoceno tardío final. Para tal fin, se consideró a DV1 como un referente adecuado debido a la excelente conservación de rasgos y estructuras (Moreno y Pérez Ruíz, 2010; Peralta González et al., 2014). y se utilizaron como indicadores de estructuración espacial interna rasgos como fogones y huellas de poste, estructuras conformadas por bloques de basalto, y patrones de distribución formados por el registro artefactual y arqueofaunístico. La utilización de manera conjunta de técnicas geoestadísticas y aproximaciones sobre procesos postdepositacionales, ha permitido observar tendencias organizativas. Se propone que aquellas concentraciones de material como en el caso de DV1 están asociadas a estructuras de combustión, o a bloques de basalto en BJ3 dan cuenta de distribuciones y asociaciones estadísticamente significativas que se vinculan con prácticas de ordenamiento interno del espacio, como los sectores de descarte secundario (Schiffer, 1972). Estas distribuciones sugieren, además, la articulación de actividades de talla y de procesamiento de recursos faunísticos en relación con áreas de combustión.

Los contextos estudiados fueron definidos como sitios de actividades múltiples o bases residenciales, en donde se efectuaron tareas como la confección de instrumentos líticos, procesamiento y consumo de recursos faunísticos. La excepción es BPR12, que, debido a su historia tafonómica, no pudo establecerse una pauta funcional.

La variabilidad observada en los sitios refleja un uso mucho más intensivo del fondo del valle (DV1 y BJ3) en donde fue posible reconocer una fuerte estructuración intrasitio, frente a BPR12, localizado en las laderas del bajo y que aparentaba tener una mayor estructura interna.

En base a los resultados obtenidos, se elaboró un referente de estructuración intrasitio que oriente futuras investigaciones. Se trata de un modelo predictivo que conforma una representación esquemática de la distribución y dispersión de indicadores arqueológicos. Las medidas promedio permiten pensar las dimensiones en las cuales sería esperable encontrar algunas correlaciones entre agrupaciones, rasgos y/o estructuras.

Se reconoció que la pauta estaría condicionada por la orientación de los vientos predominantes en el área, pero también se pudo reconocer una posible adecuación de las estructuras de reparo en función del cambio de estos en el transcurso del día.

Los resultados obtenidos permiten postular que con posterioridad al $1500 \mathrm{AP}$ se produjeron ocupaciones de alta densidad en la parte baja del valle. Se observaron sitios de grandes dimensiones, intensamente ocupados, y con una fuerte estructuración interna. Mientras que los sitios detectados en las laderas, se caracterizan por sus pequeñas dimensiones y la baja intensidad con las que habrían sido ocupados. Las características arqueológicas completamente diferentes de estas dos unidades del paisaje del Bajo de Sarmiento, conducen a pensar si existió un uso diferencial del fondo del valle y las laderas por parte de los grupos humanos.

Por último, quedaron planteados interrogantes que aún subsisten en la interpretación de los contextos arqueológicos analizados y que permiten esbozar futuras perspectivas de investigación. Las nuevas preguntas se orientarán a conocer si existieron cambios en las estrategias de ocupación del espacio entre el bloque temporal que comprende desde el 5000 AP y 1500 , en sitios emplazados en las laderas de acuerdo al modelo de evolución del paleolago y el Holoceno tardío final (fondo del valle y secundariamente laderas). De este modo, la expectativa es que las ocupaciones previas al 1500 AP fueran eventos de baja densidad, sin estructuración intrasitio y carentes de acondicionamiento interno. Por el contrario, en las ocupaciones posteriores al $1500 \mathrm{AP}$ se espera un aumento en el uso planificado de sectores del espacio, observado en la adecuación espacial intrasitio, a través de una mayor definición y diferenciación de lugares (sensu Binford, 1982), como se verificó en los sitios DV1 y BJ3 (Moreno y Peralta González, 2020; Peralta González et al., 2014).

\section{Referencias citadas}

» Baxter, M. J. (2015). Spatial k-means clustering in archaeology-variations on a theme. Working paper. Manuscrito inédito. https://www.academia. edu/18142974/ 
» Binford, L. (1982). The archaeology of place. Journal of Anthropological Archaeology, 1, 5-40.

» Binford, L., (1995). En Búsqueda del Pasado, Barcelona: Crítica.

» Borrero, L. A., Lanata, J. L. y Ventura, B. N. (1992). Distribución de hallazgos aislados en Piedra del Águila. En L. A. Borrero y J. L. Lanata (Eds.), Análisis espacial en la arqueología patagónica (pp. 9-20). Buenos Aires: Ediciones Ayllu.

"Ducke, B. (2015). Spatial cluster detection in Archaeology: Current theory and practice. En J. A. Barceló e I. Bogdanovic (Eds.), Mathematics and Archaeology (pp. 353-368). Boca Raton: CRC Press.

"Hodder, I. y Orton, C. (1990). Análisis Espacial en Arqueología. Barcelona: Crítica.

" Maximiano Castillejo, A. (2013). Datos óptimos para la caracterización espacial y temporal de la variabilidad arqueológica a escala intra-site. GeoFocus. Revista Internacional de Ciencia y Tecnología de la Información Geográfica, 13(1), 131-153. https://www.geofocus.org/ index.php/geofocus/article/view/264

》 Maximiano Castillejo, A. (2016). Análisis espacial arqueológico: Una revisión desde la Geoestadística. En C. Mínguez García y E. Capdevila (Eds.), Manual de Tecnologías de la Información Geográfica Aplicadas a la
Arqueología (pp. 203-240). Madrid: Comunidad de Madrid y Museo Arqueológico Regional.

» Moreno, J. E. y Peralta González, S. (2020). Estructuración intrasitio, registro arqueofaunístico e historia tafonómica del sitio Boliche de jerez 3 (Lago Colhué Huapi, Chubut). En J. Gómez Otero, A. Svoboda y A. Banegas (Eds.), Arqueología de la Patagonia: el pasado en las arenas (pp. 433- 441). Puerto Madryn: Instituto de Diversidad y Evolución Austral (IDEAus), Centro Nacional Patagónico (CENPAT), CONICET.

» Moreno, J. y Pérez Ruíz, H. (2010). Evidencias de utilización prehispánica de recursos fluviales en la cuenca del Lago Musters (Chubut, Argentina). En J. Bárcena y H. Chiavaza (Eds.), Actas del XVII congreso Nacional de Arqueología Argentina (pp. 345-350). Mendoza: Instituto de Ciencias Humanas, Sociales y Ambientales (INCIHUSA), CONICET.

» Peralta González, S., Moreno, J. E. y Pérez Ruíz, H. (2014). La casa está en orden. Análisis espacial intrasitio de Delta del Arroyo Vulcana 1 (Lago Musters, Chubut, Argentina) y la movilidad de los cazadores-recolectores en Patagonia Central durante el Holoceno Tardío. Magallania, 42(2), 141-153. http://www.magallania.cl/index.php/magallania/ article/view/625

» Schiffer, M. (1972). Archaeological context and systemic context. American Antiquity 37(2), 156-165. 